\title{
Re-evaluation of the serotypes of Serratia marcescens and separation into two schemes based on lipopolysaccharide ( 0 ) and capsular polysaccharide $(K)$ antigens
}

\author{
Hazel M. Aucken, ${ }^{1}$ Stephen G. Wilkinson ${ }^{2}$ and Tyrone L. Pitt ${ }^{1}$ \\ Author for correspondence: Hazel M. Aucken. Tel: +441812004400 ext. 4232 . Fax: +44 1812007449. \\ e-mail: haucken@phls.co.uk
}

\footnotetext{
1 Laboratory of Hospital Infection, Central Public Health Laboratory, 61 Colindale Avenue, London NW9 5HT, UK

2 School of Chemistry, The University, Hull HU6 7RX, UK
}

\begin{abstract}
Chemical and serological analysis has revealed that many of the 290 serotype reference strains of Serratia marcescens contain both neutral and acidic polysaccharides which correspond to LPS $O$ antigens and capsular $K$ antigens, respectively. New $O$ and $K$ antigen typing schemes have therefore been devised, based on the known chemical structures of the surface polysaccharides of the organism. These schemes were designed to allow the specific detection of these antigens on unknown strains using ELISAs. 0 antigens were detected using whole cells cultured in broth then autoclaved to remove capsular material, while $K$ antigens were detected using formolized whole cells which had been cultured on glycerol agar to enhance capsule production. After testing with the 29 reference strains as well as $\mathbf{4 2 3}$ distinct clinical strains, it was apparent that different aspects of chemical structure were associated with different degrees of serological reactivity and the typing schemes were modified further to accommodate this. In general, the 0 antigen repeating unit structures were chemically simple with di- or trisaccharide backbones. Serological specificity was often provided solely by the presence or absence of an 0 -acetyl substituent, or a change in the linkage between two sugar residues. Five of the $O$ serotypes in the new scheme were represented by 12 of the 29 reference strains, while three reference strains lacked $O$ antigens altogether, resulting in the elimination of 10 of the original 0 types. In contrast, the $K$ antigen repeating unit structures were more complex and chemically diverse, having at least four sugar residues. Three $K$ types were each seen in two reference strains while 12 of the 29 reference strains were acapsular. Thus, the resulting schemes contain 190 types and $14 \mathrm{~K}$ types and allow the definitive serotype identification of $S$. marcescens.
\end{abstract}

Keywords: Serratia marcescens, LPS, capsules, serotyping, O and K antigens

\section{INTRODUCTION}

Serratia marcescens is an opportunist Gram-negative bacterium that causes outbreaks of infection, and occasionally death, in hospitalized patients. The nature and extent of an outbreak can be determined by investigating the strain-relatedness of isolates using epidemiological typing methods. Such investigations

Abbreviations: KA, King's agar; NA, nutrient agar; NRS, normal rabbit serum; TSB, tryptone soya broth. will not only identify episodes of cross-infection, but also will reveal possible common sources and unrelated sporadic infections (Farmer et al., 1976). Serotyping schemes based on the O antigens of LPS or capsular K antigens have proved extremely useful for typing other Gram-negative species such as Escherichia coli and Klebsiella spp. (Ørskov \& Ørskov, 1984, 1992). Generally, these antigens are highly stable and therefore are often used as 'gold standard' characteristics since isolates with different serotypes can confidently be assumed to be different strains in the vast majority of cases. Furthermore, by providing definitive type labels, 
Table 1. New serotype designations of the $29 \mathrm{~S}$. marcescens 0 serotype reference strains

\begin{tabular}{|c|c|c|c|c|}
\hline $\begin{array}{l}\text { Original } \\
\text { serotype }\end{array}$ & $\begin{array}{l}\text { Reference } \\
\text { strain }\end{array}$ & Strain reference & Polysaccharide reference & New serotype* \\
\hline $\mathrm{O} 1$ & $866-57$ & Davis \& Woodward (1957) & $\begin{array}{l}\text { Furn \& Wilkinson (1985); } \\
\text { Johansson et al. (1995) }\end{array}$ & O19:K1 \\
\hline $\mathrm{O} 2$ & $868-57$ & Davis \& Woodward (1957) & Oxley \& Wilkinson (1988f, 1992b) & $\mathrm{O} 2: \mathrm{K} 2$ \\
\hline $\mathrm{O} 3$ & $863-57$ & Davis \& Woodward (1957) & Oxley \& Wilkinson (1989b, 1992b) & $\mathrm{O} 2: \mathrm{K} 3$ \\
\hline $\mathrm{O} 4$ & $864-57$ & Davis \& Woodward (1957) & Oxley \& Wilkinson (1988c, e) & $\mathrm{O} 4: \mathrm{K} 4$ \\
\hline O5 & $867-57$ & Davis \& Woodward (1957) & Oxley \& Wilkinson (1988b) & $\mathrm{O} 5: \mathrm{K} 28$ \\
\hline O6 & $862-57$ & Davis \& Woodward (1957) & $\begin{array}{l}\text { Brigden \& Wilkinson (1985a); } \\
\text { Brigden } \text { et al. (1985) }\end{array}$ & O6:K14 \\
\hline O7 & $843-57$ & Ewing et al. (1959) & Oxley \& Wilkinson (1988c) & O6:K7 \\
\hline O8 & $1604-57$ & Ewing et al. (1959) & Oxley \& Wilkinson (1986) & O8:K - \\
\hline O9 & $4534-60$ & Ewing et al. (1959) & Oxley \& Wilkinson (1987) & O26:K9 \\
\hline O10 & $1289-59$ & Sedlãk et al. (1965) & Oxley \& Wilkinson (1989c) & $\mathrm{O} 10: \mathrm{K}-$ \\
\hline O11 & $1914-63$ & Ewing et al. (1962) & - & $\mathrm{O}-: \mathrm{K}-$ \\
\hline $\mathrm{O} 12$ & $6320-58$ & Ewing et al. (1962) & Brigden et al. (1985) & O14:K12 \\
\hline $\mathrm{O} 13$ & $3607-60$ & Ewing et al. (1962) & Oxley \& Wilkinson (1988a) & $\mathrm{O}-: \mathrm{K} 13$ \\
\hline O14 & $4444-60$ & Ewing et al. (1962) & Brigden \& Wilkinson $(1983,1985 a)$ & O14:K14 \\
\hline 015 & $4523-60$ & Ewing et al. (1962) & Oxley \& Wilkinson (1988d, 1989a) & O26:K15 \\
\hline O16 & IP687 & Le Minor \& Pigache (1978) & Oxley \& Wilkinson (1989d) & O16:K- \\
\hline O17 & IP374 & Le Minor \& Pigache (1978) & Oxley \& Wilkinson (1990b) & O19:K- \\
\hline O18 & IP333 & Le Minor \& Pigache (1978) & Oxley \& Wilkinson (1989e, 1991d) & O18:K18 \\
\hline O19 & IP451 & Le Minor \& Pigache (1978) & Oxley \& Wilkinson (1990b) & O19:K- \\
\hline $\mathrm{O} 20$ & IP785 & Le Minor \& Pigache (1978) & Oxley \& Wilkinson (1989d) & $\mathrm{O} 20: \mathrm{K}-$ \\
\hline $\mathrm{O} 21$ & IP1521 & $\begin{array}{l}\text { Le Minor \& Sauvageot- } \\
\text { Pigache (1981) }\end{array}$ & Oxley \& Wilkinson (1991b) & $\mathrm{O} 21: \mathrm{K}-$ \\
\hline $\mathrm{O} 22$ & HOM SH59 & Traub (1981) & Oxley \& Wilkinson (1990c, 1992a) & $\mathrm{O} 22: \mathrm{K} 22$ \\
\hline $\mathrm{O} 23$ & IP1160 & Le Minor et al. (1983) & Oxley \& Wilkinson $(1990 a, d)$ & $\mathrm{O} 23: \mathrm{K} 23$ \\
\hline $\mathrm{O} 24$ & HOM US1 & Traub (1985) & Oxley \& Wilkinson (1989f) & $\mathrm{O} 24: \mathrm{K}-$ \\
\hline $\mathrm{O} 25$ & P12 & Traub (1991) & Aucken et al. (1995) & $\mathrm{O}-: \mathbf{K}-$ \\
\hline $\mathrm{O} 26$ & SB15 & Traub (1991) & Aucken et al. (1995) & O26: $\mathrm{K}-$ \\
\hline $\mathrm{O} 27$ & S1254 & Gaston \& Pitt (1989b) & Oxley \& Wilkinson (1991a) & $\mathbf{O} 27: \mathbf{K}-$ \\
\hline $\mathrm{O} 28$ & S3255 & Gaston \& Pitt (1989b) & Oxley \& Wilkinson (1991c) & $\mathrm{O} 28: \mathrm{K} 28$ \\
\hline $\mathrm{O} 29$ & S111 & Holst et al. (1997) & Holst et al. (1997) & $\mathrm{O} 29: \mathrm{K} 4$ \\
\hline
\end{tabular}

${ }^{*} \mathrm{O}-$, rough LPS; $\mathrm{K}-$, acapsular.

these methods may allow the identification of virulent types, as well as investigations into the global epidemiology of a species.

Most serological typing schemes, including the 29 currently recognized $S$. marcescens $O$ serotypes (see list of strain references, Table 1), were derived empirically, by dividing strain collections into groups based on shared agglutination reactions with their corresponding antisera and selecting one serotype reference strain for each group. However, the $S$. marcescens scheme has always suffered from cross-reactions which have proved difficult to resolve. Gaston $\&$ Pitt (1989a) suggested that this scheme must include non-LPS antigens, since SDSPAGE and immunoblotting revealed that two of the reference strains are rough (i.e. lack $O$ antigen) and several pairs of reference strains have the same LPS antigen. Chemical analysis of polymers present in 'LPS' extracts from the reference strains has shown that the polysaccharide repeating units can be divided into neutral and acidic structures and that many of the reference strains possess both (Wilkinson, 1990). It has been suggested that the LPS $O$ antigens correlate with the neutral polysaccharides (Gaston et al., 1988; Gaston \& Pitt, 1989a) while the acidic polysaccharides have now been shown to correspond to capsular antigens (Aucken et al., 1997). The current study was undertaken to rationalize the existing $O$ typing scheme and to propose a complementary capsular $\mathrm{K}$ typing scheme. We present here the immunochemical basis of these $\mathrm{O}$ and $\mathrm{K}$ antigen schemes for the serological typing of $S$. marcescens.

\section{METHODS}

Bacterial strains. The 29 reference strains were as listed in Table 1 . For clarity, new serotype designations are printed in bold typescript in both text and tables. In addition, 423 clinical 
Table 2. O antigen serotyping scheme for $S$. marcescens and adsorptions necessary to obtain serospecificity

\begin{tabular}{|c|c|c|c|c|}
\hline $\begin{array}{l}\text { Reference } \\
\text { strain to }\end{array}$ & $\begin{array}{l}\text { Serotype } \\
\text { antigen }\end{array}$ & \multicolumn{2}{|c|}{$\begin{array}{l}\text { Serotype antibody } \\
\text { to be adsorbed }\end{array}$} & Adsorbing strain \\
\hline $868-57$ & $\mathrm{O} 2$ & O21 & K2 & IP1521 (O21:K-) + S117 (O19:K2) \\
\hline $864-57$ & O4 & $\mathrm{O} 27$ & K4 & $\mathrm{S} 1254(\mathrm{O} 27: \mathrm{K}-)+\mathrm{S} 1725(\mathrm{O}-: \mathrm{K} 4)$ \\
\hline $867-57$ & O5 & - & K28 & S3255 (O28: K28) \\
\hline $862-57$ & O6 & - & K14 & 4444-60 (O14:K14) \\
\hline $1604-57$ & 08 & - & - & $4444-60(\mathrm{O} 14: \mathrm{K} 14)^{*}$ \\
\hline $1289-59$ & O10 & $\mathrm{O} 22$ & - & HOM SH59 (O22: K22) \\
\hline $4444-60$ & 014 & - & K14 & $862-57$ (O6:K14) \\
\hline IP687† & 016 & O20 & - & IP785 (O20: $K-)$ \\
\hline IP333 & O18 & O29 & K18 & S111 (O29:K4) (O18-:K18 unavailable) \\
\hline IP451 & O19 & $\mathrm{O} 26$ & - & $4534-60(\mathrm{O} 26: \mathrm{K} 9)$ \\
\hline IP785 & $\mathbf{O 2 0}$ & - & - & $4444-60(\mathrm{O} 14: \mathrm{K} 14)^{*}$ \\
\hline IP1521 & O21 & $\mathrm{O} 2+\mathrm{O} 3$ & - & $868-57(\mathrm{O} 2: \mathrm{K} 2)+863-57(\mathrm{O} 2: \mathrm{K} 3)$ \\
\hline HOM SH59 & $\mathrm{O} 22$ & O10 & K22 & $1289-59(\mathrm{O} 10: \mathrm{K}-)+\mathrm{S} 2164(\mathrm{O}-: \mathrm{K} 22)$ \\
\hline IP1160 & $\mathbf{O} 23$ & - & $\mathbf{K} 23$ & S4093 (O28:K23) \\
\hline HOM US1 & O24 & - & - & $4444-60(\mathrm{O} 14: \mathrm{K} 14)^{*}$ \\
\hline SB15 & $\mathbf{O 2 6}$ & O19 & - & IP451 (O19:K-) \\
\hline S1254 & $\mathrm{O} 27$ & O4 & - & $864-57(\mathrm{O} 4: \mathrm{K} 4)$ \\
\hline S3255-1‡ & $\mathbf{O} 28$ & - & - & None \\
\hline S111 & O29 & O18 & K4 & IP333 (O18:K18) + 864-57 (O4:K4) \\
\hline
\end{tabular}

* Used as default adsorbing strain - could be omitted.

† Strain IP687 contains two neutral polysaccharides (Oxley \& Wilkinson, 1989c).

$\ddagger$ Acapsular variant.

strains were selected from over 3000 isolates sent to the Laboratory of Hospital Infection between 1 January 1980 and 30 June 1990 for epidemiological typing. One representative of each distinct strain within each incident of hospital infection was chosen using the $\mathrm{O}$ agglutination and phage typing results obtained at the time of initial investigation (Pitt et al., 1980). An incident was defined as one or more isolates sent for typing from the same centre and isolates were considered to represent distinct strains if they differed in serotype or if they were of the same serotype but differed by at least three major reactions in their patterns of phage sensitivities. These criteria were more stringent than those normally recommended for phage typing (Pitt et al., 1980) to reduce the likelihood of selecting isolates representing the same strain. Among these clinical strains were some that were subsequently selected for further adsorption of the typing sera. These were S117 (O19:K2), S1072 (O29:K4), S1725 (O-:K4), S2164 (O-:K22) and S4093 (O28:K23).

Phage-resistant acapsular variants of 11 of the 29 reference strains had been produced for a previous study (Aucken $e t$ al., 1997). These variants were used here for adsorption of $O$ antibodies from sera to the encapsulated reference strains to produce K-specific typing reagents. Prior to each use, each variant was tested both for phage resistance and for absence of capsule in the Quellung reaction and reselected with the appropriate phage when necessary.

All cultures were maintained on nutrient agar and stored at $-20^{\circ} \mathrm{C}$ on $2 \mathrm{~mm}$ glass beads in nutrient broth containing $20 \%$ (v/v) glycerol.
Polysaccharides. LPS, neutral polysaccharides and acidic polysaccharides from the serotype reference strains were prepared from cells grown in nutrient broth at $37^{\circ} \mathrm{C}$ for $16 \mathrm{~h}$. After preparation of cell walls (Brigden \& Wilkinson, 1985a) and the extraction of lipids with chloroform/methanol $(2: 1$, $\mathrm{v} / \mathrm{v}$ ), surface polysaccharides were isolated by treatment with hot aqueous phenol (Westphal \& Jann, 1965). Reference strains $\mathrm{O} 2, \mathrm{O} 3$ and $\mathrm{O} 21$ were unusual in that the LPS remained in the phenolic phase rather than the aqueous phase (Oxley \& Wilkinson, 1991b, 1992b). Lipid A was released from the purified LPS by mild acid hydrolysis and the watersoluble polymeric products were isolated by Sephadex G-50 chromatography. Where appropriate, neutral and acidic polysaccharides were separated by chromatography on DEAE-Sepharose CL-6B (Brigden \& Wilkinson, 1985a). In most cases, their structures were determined by component analysis, NMR spectroscopy, methylation analysis and appropriate chemical degradations. Detailed information is presented in the polysaccharide references cited in Table 1.

Antisera. Rabbit antisera were raised against the reference strains as previously described using cells which had been either heated at $100^{\circ} \mathrm{C}$ for $1 \mathrm{~h}$ or autoclaved at $121^{\circ} \mathrm{C}$ for 15 min (Aucken et al., 1996). Normal rabbit control serum (NRS) was collected by exsanguination of a non-immunized rabbit.

Serum adsorptions. The bacterial strains used for adsorption of the reference antisera were as listed in Tables 2 and 3. Kspecific reagents were produced by adsorption of $\mathrm{O}$ antibodies using NA-grown cells, while $\mathrm{O}$-specific reagents were pro- 
Table 3. Proposed K antigen serotyping scheme for S. marcescens

\begin{tabular}{|c|c|c|c|}
\hline $\begin{array}{l}\text { Reference strain } \\
\text { to which serum is } \\
\text { raised }\end{array}$ & $\begin{array}{c}\text { Serotype } \\
\text { antigen }\end{array}$ & $\begin{array}{c}\text { Serotype } \\
\text { antibody to be } \\
\text { adsorbed }\end{array}$ & Adsorbing strain \\
\hline $866-57$ & $\mathbf{K} 1$ & O19 & $866-57-2^{*}(\mathrm{O} 19: \mathrm{K}-)$ \\
\hline $868-57$ & $\mathbf{K} 2$ & $\mathbf{O} 2$ & $868-57-4^{*}(\mathrm{O} 2: \mathrm{K}-)$ \\
\hline $863-57$ & $\mathbf{K 3}$ & $\mathbf{O} 2$ & $863-57-1^{*}(\mathrm{O} 2: \mathrm{K}-)$ \\
\hline $864-57$ & K4 & O4 & $864-57-1 *(\mathrm{O} 4: \mathrm{K}-)$ \\
\hline $843-57$ & K7 & O6 & $843-57-1^{*}(\mathrm{O6}: \mathrm{K}-)$ \\
\hline $4534-60$ & K9 & O26 & $4534-60-1^{*}(\mathrm{O} 26: \mathrm{K}-)$ \\
\hline $6320-58$ & K12 & O14 & $4444-60(\mathrm{O} 14: \mathrm{K} 14)$ \\
\hline $3607-60$ & K13 & Rough LPS & $1914-63$ (O- :K11) \\
\hline $4444-60$ & K14 & O14 & 6320-57 (O14:K12) \\
\hline $4523-60$ & K15 & 026 & $4523-60-2^{*}(\mathrm{O} 26: \mathrm{K}-)$ \\
\hline IP333 & K18 & O18 & S1072 (O29:K4) \\
\hline HOM SH59 & K22 & $\mathbf{O} 22$ & $1289-59(\mathrm{O} 10: \mathrm{K}-)$ in lieu of $\mathrm{O} 22: \mathrm{K} 22-$ \\
\hline IP1160 & K23 & $\mathbf{O 2 3}$ & IP1160-2* (O23:K-) \\
\hline S3255 & K28 & $\mathbf{O} 28$ & $\mathrm{~S} 3255-1^{*}(\mathrm{O} 28: \mathrm{K}-)$ \\
\hline
\end{tabular}

*Acapsular variant of reference strain.

duced using growth from King's A agar (KA, King et al., 1954) which contains glycerol and enhances capsule production (Aucken et al., 1997). Overnight bacterial growth at $30^{\circ} \mathrm{C}$ was harvested from four $15 \mathrm{~cm}$ plates into approximately $25 \mathrm{ml}$ $0.4 \%$ formol saline. The cells were pelleted by centrifugation at $2500 \mathrm{~g}$ for $1 \mathrm{~h}$ and thoroughly resuspended in $4.5 \mathrm{ml}$ PBS containing $0.02 \%$ Merthiolate as a preservative. After the addition of $0.5 \mathrm{ml}$ of the serum to be adsorbed, the suspension was incubated at $37^{\circ} \mathrm{C}$ for $2-3 \mathrm{~h}$ on a rotary mixer and then overnight at $4^{\circ} \mathrm{C}$. The suspension was centrifuged at $27000 \mathrm{~g}$ for $1 \mathrm{~h}$, filtered through a $2 \mu \mathrm{m}$ membrane filter and stored at $-20^{\circ} \mathrm{C}$.

ELISA. The ELISA for the detection of $\mathrm{O}$ antigens employed autoclaved whole cell cultures grown in tryptone soya broth (TSB) as the coating antigen and an alkaline phosphatase detection system as described previously (Aucken et al., 1995). The optical densities were read at $405 \mathrm{~nm}$ using a Titertek ELISA plate-reader. This assay was modified for the detection of $\mathrm{K}$ antigen by the use of KA-grown cells exposed to $0.4 \%$ formol saline for approximately $1 \mathrm{~h}$ at room temperature as coating antigen (Aucken et al., 1997). NRS at a dilution of 1 in 500 and $\mathrm{PBS}$ alone were used as negative controls, producing $\mathrm{OD}_{405}$ readings of 0.3 and $0 \cdot 15$, respectively. Serum titres were recorded as the highest dilution giving a reading of 0.5 and were performed on three separate occasions. Working concentrations for each of the adsorbed sera were based on the titre, then optimized according to the pattern of positive and negative results seen with all reference strains. Assays using clinical strains were performed once only using serum panels at the previously established working dilutions. An individual test was considered positive when the $\mathrm{OD}_{405}$ was $\geqslant 0 \cdot 6$. Tests on strains with negative or anomalous results were repeated and investigated by SDS-PAGE.

Quellung reaction. The Quellung reaction was seen when corresponding antiserum and bacterial cells were mixed on a microscope slide then viewed with phase-contrast illumination under a $\times 100$ oil-immersion objective (Aucken et al., 1995). A distinct grey halo around the short, dark bacilli indicated recognition of capsule by the antiserum, since antibody binding produces a change in the refractive index of the capsular material, thus identifying the capsular serotype of the organism.

Cetavlon technique. Ørskov's method (Ørskov, 1976) for the indirect, non-immunological detection of acidic polysaccharides was as previously described (Aucken et al., 1997). Briefly, cell suspensions of approximately $10^{9}$ c.f.u. $\mathrm{ml}^{-1}$ were heated at $60^{\circ} \mathrm{C}$ and subjected to horizontal electrophoresis, then allowed to diffuse towards a trough of $0.2 \%$ Cetavlon (hexadecyltrimethylammonium bromide, Sigma) which precipitates acidic but not neutral polysaccharides.

SDSPAGE. The purified LPS extracts described above, or alternatively cruder extracts prepared using proteinase $\mathrm{K}$ (Hitchcock \& Brown, 1983), were separated by SDS-PAGE and the profiles revealed either by silver staining (Aucken $\&$ Pitt, 1993) or by electrophoretic transfer to nitrocellulose paper and subsequent detection by immunoblotting (Aucken et al., 1995).

\section{RESULTS AND DISCUSSION}

\section{Antigen composition and structure}

The chemical structures (or compositional data in some cases) established for the repeating units of polysaccharides isolated from the reference strains originally designated $\mathrm{O} 1-\mathrm{O} 29$ are summarized in Tables 4 and 5 . The principal finding was that 14 strains produced two types of polymer : one polysaccharide made up of neutral sugars, the second polysaccharide containing an acidic residue. The remaining strains had neutral polysaccharides alone, except for reference strains O11 and O13 (which possessed only an acidic polymer) and $\mathrm{O} 25$ (from which no polymer was isolated). Six different neutral repeating unit structures were found in pairs of reference strains, namely $\mathrm{O} 2$ and $\mathrm{O} 3, \mathrm{O} 6$ and $\mathrm{O} 7, \mathrm{O} 12$ and $\mathrm{O} 14$, 
Table 4. Neutral polysaccharide repeating units of S. marcescens

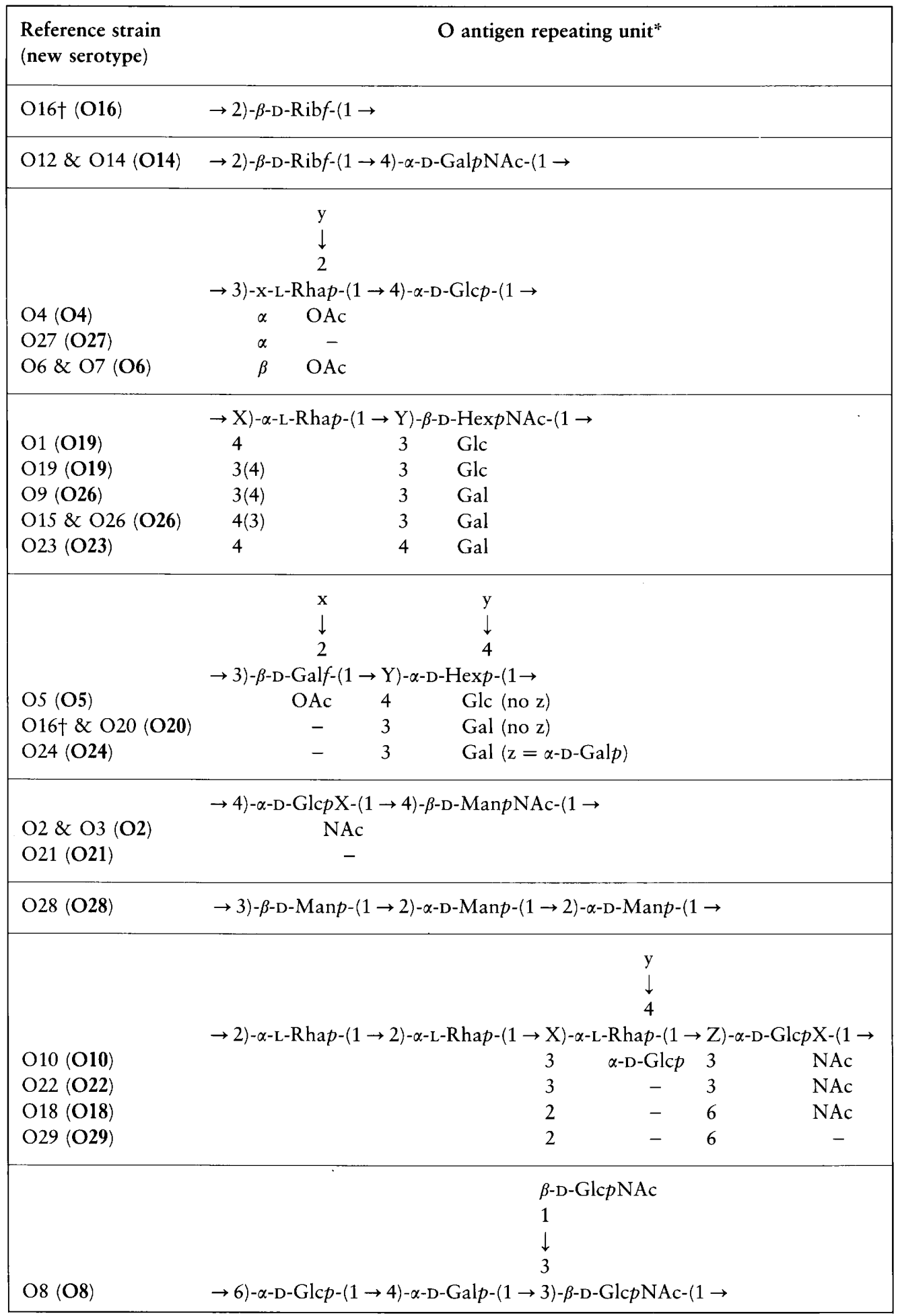

*Abbreviations: Gal, galactose; GalNAc, N-acetylgalactosamine; Glc, glucose; GlcNAc, N-acetylglucosamine; Hex, hexose; HexNAc, N-acetylhexosamine; Man, mannose; ManNAc, N-acetylmannosamine; Rha, rhamnose; Rib, ribose.

†Two neutral polysaccharides (O16 and O20) found in the O16 reference strain IP687. 
Table 5. Acidic polysaccharide repeating units of S. marcescens

\begin{tabular}{|c|c|c|}
\hline $\begin{array}{l}\text { Reference } \\
\text { strain } \\
\text { (new serotype) }\end{array}$ & $\mathrm{K}$ antigen repeating unit ${ }^{*}$ & \\
\hline O1 (K1) & Pentasaccharide of Glc, Man, GlcNAc and GalA & $+\mathrm{OAc}$ \\
\hline \multirow[t]{2}{*}{$\mathrm{O} 2(\mathrm{~K} 2)$} & $\rightarrow 3)-\alpha$-D-Rhap-(1 $\rightarrow 3)-\beta$-D-Galp- $(1 \rightarrow 3)-\alpha$-D-Rhap- $(1 \rightarrow 4)-\alpha-\mathrm{D}-\mathrm{Gal} p \mathrm{~A}-(1 \rightarrow$ & $+\mathrm{OAc}$ \\
\hline & $\begin{array}{c}\beta \text {-D-Man } p \\
1 \\
\downarrow \\
4 \\
\rightarrow 3)-\alpha-\mathrm{D}-\operatorname{Man} p-(1 \rightarrow 3)-\alpha-\mathrm{D}-\mathrm{Gal} p-(1 \rightarrow 2)-\alpha-\mathrm{D}-\mathrm{Glc} p \mathrm{~A}-\langle 1 \rightarrow 3)-\alpha-\mathrm{D}-\mathrm{Man} p-(1 \rightarrow\end{array}$ & $+\mathrm{OAc}$ \\
\hline $\mathrm{O} 4(\mathbf{K 4})$ & $\begin{array}{c}\bigwedge_{46} \\
\alpha-\mathrm{DyrA}-\mathrm{Gal} p \\
1 \\
\downarrow \\
3 \\
\rightarrow 3)-\alpha-\mathrm{D}-\operatorname{Man} p-(1 \rightarrow 3)-\beta-\mathrm{D}-\mathrm{Gal} p-(1 \rightarrow 2)-\alpha-\mathrm{D}-\operatorname{Man} p-(1 \rightarrow\end{array}$ & $+\mathrm{OAc}$ \\
\hline $\begin{array}{l}\text { O5 (K28) } \\
\text { O28 (K28) } \\
\text { O23a (K23) } \\
\text { O23b (K23) }\end{array}$ & $\begin{array}{l}\text { Hexasaccharide of Glc, Man, GlcA and an amino sugar } \\
\text { Possibly O23 backbone plus the O5 amino sugar linked to GlcA } \\
\begin{array}{l}\rightarrow 3)-\alpha-\mathrm{D}-\mathrm{Man} p-(1 \rightarrow 3)-\alpha-\mathrm{D}-\mathrm{Gal} p-(1 \rightarrow 3)-\alpha-\mathrm{D}-\mathrm{Gal} p-(1 \rightarrow 2)-\alpha-\mathrm{D}-\mathrm{Glc} p \mathrm{~A}-(1 \rightarrow \\
\rightarrow 3)-\alpha-\mathrm{D}-\mathrm{Man} p-(1 \rightarrow 3)-\alpha-\mathrm{D}-\mathrm{Gal} p-(1 \rightarrow 3)-\alpha-\mathrm{D}-\mathrm{Gal} p-(1 \rightarrow 2)-\alpha-\mathrm{D}-\mathrm{Glc} p \mathrm{~A}-(1 \rightarrow \\
\uparrow \\
6 \\
\text { L-Glu }\end{array}\end{array}$ & $+\mathrm{OAc}$ \\
\hline O6 \& O14 (K14) & $\begin{array}{c}\alpha-\mathrm{D}-\mathrm{Glc} p \mathrm{~A} \\
1 \\
\downarrow \\
4 \\
\rightarrow 4)-\alpha-\mathrm{D}-\mathrm{Man} p-(1 \rightarrow 3)-\alpha-\mathrm{D}-\mathrm{Glc} p-(1 \rightarrow 3)-\beta \text {-D-Glc } p-(1 \rightarrow\end{array}$ & $+\mathrm{OAc}$ \\
\hline $\mathrm{O} 7(\mathbf{K} \mathbf{7})$ & Hexasaccharide of Glc, Man, Rha, Gal and GlcA & $+\mathrm{OAc}$ \\
\hline O11 (none) & Complex oligosaccharide of Man, Gal, Rha and GalA & \\
\hline $\mathrm{O} 12(\mathrm{~K} 12)$ & Tetrasaccharide of Glc, Man, Gal and GlcA & \\
\hline O13 (K13) & $\begin{array}{c}\beta \text {-D-GlcpNAc } \\
1 \\
\downarrow \\
4 \\
\rightarrow 3)-\alpha \text {-D-Man } p-(1 \rightarrow 3)-\beta \text {-D-Glcp- }(1 \rightarrow 3)-\beta \text {-D-GlcpA- }(1 \rightarrow 3)-\alpha-\mathrm{D}-\mathrm{Gal} p-(1 \rightarrow 6)-\alpha-\mathrm{D}-\mathrm{Man} p-(1 \rightarrow\end{array}$ & \\
\hline $\mathrm{O} 15(\mathbf{K} 15)$ & 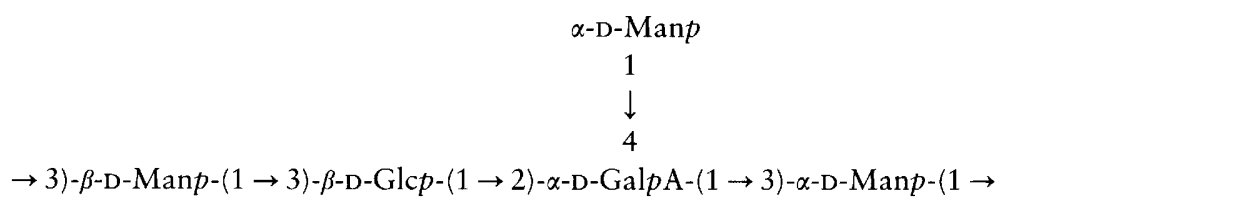 & \\
\hline
\end{tabular}


Table 5. (cont.)

\begin{tabular}{|c|c|}
\hline $\begin{array}{l}\text { Reference } \\
\text { strain } \\
\text { (new serotype) }\end{array}$ & $\mathrm{K}$ antigen repeating unit ${ }^{*}$ \\
\hline $\mathrm{O} 18(\mathbf{K} 18)$ & $\begin{array}{c}\rightarrow 3)-\beta \text {-D-Gal } p-(1 \rightarrow 4)-\alpha-\mathrm{D}-\mathrm{Man} p-(1 \rightarrow 3)-\alpha-\mathrm{D}-\mathrm{Gal} p-(1 \rightarrow \\
3 \\
\uparrow \\
1 \\
\alpha-\mathrm{D}-\mathrm{Gl} \text { cpA } \\
4 \\
\uparrow \\
1 \\
\alpha-\mathrm{L}-\mathrm{Rh} \mathrm{p} p \\
4 \\
\uparrow \\
1 \\
4-O-\text { lactyl- } \beta \text {-D-Glc } p\end{array}$ \\
\hline $\mathrm{O} 22(\mathbf{K} 22)$ & $\begin{array}{c}\beta \text {-D-Glcp } \\
1 \\
\downarrow \\
6 \\
\rightarrow 3)-\beta \text {-D-Gal } p-(1 \rightarrow 3)-\alpha \text {-D-Gal } p-(1 \rightarrow 6)-\beta \text {-D-Galf- }(1 \rightarrow \\
4 \\
\uparrow \\
1 \\
\beta \text {-D-GlcpA } \\
4 \\
\uparrow \\
1 \\
\alpha \text {-L-Rhap } \\
2 \\
\uparrow \\
1 \\
\alpha-\mathrm{D}-\mathrm{Glc} p\end{array}$ \\
\hline
\end{tabular}

*Abbreviations: Gal, galactose; GalA, galacturonic acid; GalNAc, N-acetylgalactosamine; Glc, glucose; GlcA, glucuronic acid; GlcNAc, $\mathrm{N}$-acetylglucosamine; Glu, glutamic acid; Man, mannose; PyrA, pyruvic acid; Rha, rhamnose.

$\mathrm{O} 15$ and $\mathrm{O} 26, \mathrm{O} 16$ and $\mathrm{O} 20$, and $\mathrm{O} 17$ and $\mathrm{O} 19$. The serotype heterogeneity of the first four pairs can be explained by their acidic polysaccharides, which are different for the first three pairs and absent from O26. Reference strain O16 possesses a second neutral polymer that differentiates it from strain O20. However, as no other polysaccharides were obtained from reference strains $\mathrm{O} 17$ and $\mathrm{O} 19$, some other kind of epitope must be responsible for differentiating these strains.

There were also many neutral polysaccharides sharing very similar structures. Thus, the repeating unit in reference strains $\mathrm{O} 2$ and $\mathrm{O} 3$ differs from that in strain $\mathrm{O} 21$, as do those in reference strains $\mathrm{O} 18$ and $\mathrm{O} 29$, by the presence of $\mathrm{N}$-acetylglucosamine rather than glucose, while the four neutral polymers in reference strains $\mathrm{O} 1, \mathrm{O} 17$ and $\mathrm{O} 19, \mathrm{O} 9$, and $\mathrm{O} 15$ and $\mathrm{O} 26$ all consist of a $(1 \rightarrow 3)$ - or $(1 \rightarrow 4)$-linked $\alpha$-L-rhamnose residue and $(1$ $\rightarrow 3)$-linked $N$-acetyl- $\beta$-D-glucosamine or $N$-acetyl- $\beta$-Dgalactosamine. The polysaccharides in $\mathrm{O} 27$ and $\mathrm{O} 4$ are even more similar in that the neutral polymer of the latter is an $\mathrm{O}$-acetylated version of the former. In contrast, the acidic structures are all unique to individual reference strains, with the single exception of the glucomannan in O6 and O14. Although structural data are incomplete, the only similarities observed were the backbone structures of reference strains O23 and O28 and the sharing of an amino sugar side-chain by reference strains $\mathrm{O} 5$ and $\mathrm{O} 28$. In addition to their acidity and uniqueness, these polysaccharides differ from their neutral counterparts in size and complexity, as well as in the possession of some unusual sugars. For a more detailed review of the chemistry of these polysaccharides, see Wilkinson (1990).

\section{Visualization of LPS}

The SDS-PAGE ladder patterns produced by purified LPS from the reference strains are shown in Fig. 1 (except those of strains O25, O26 and O29) and were 


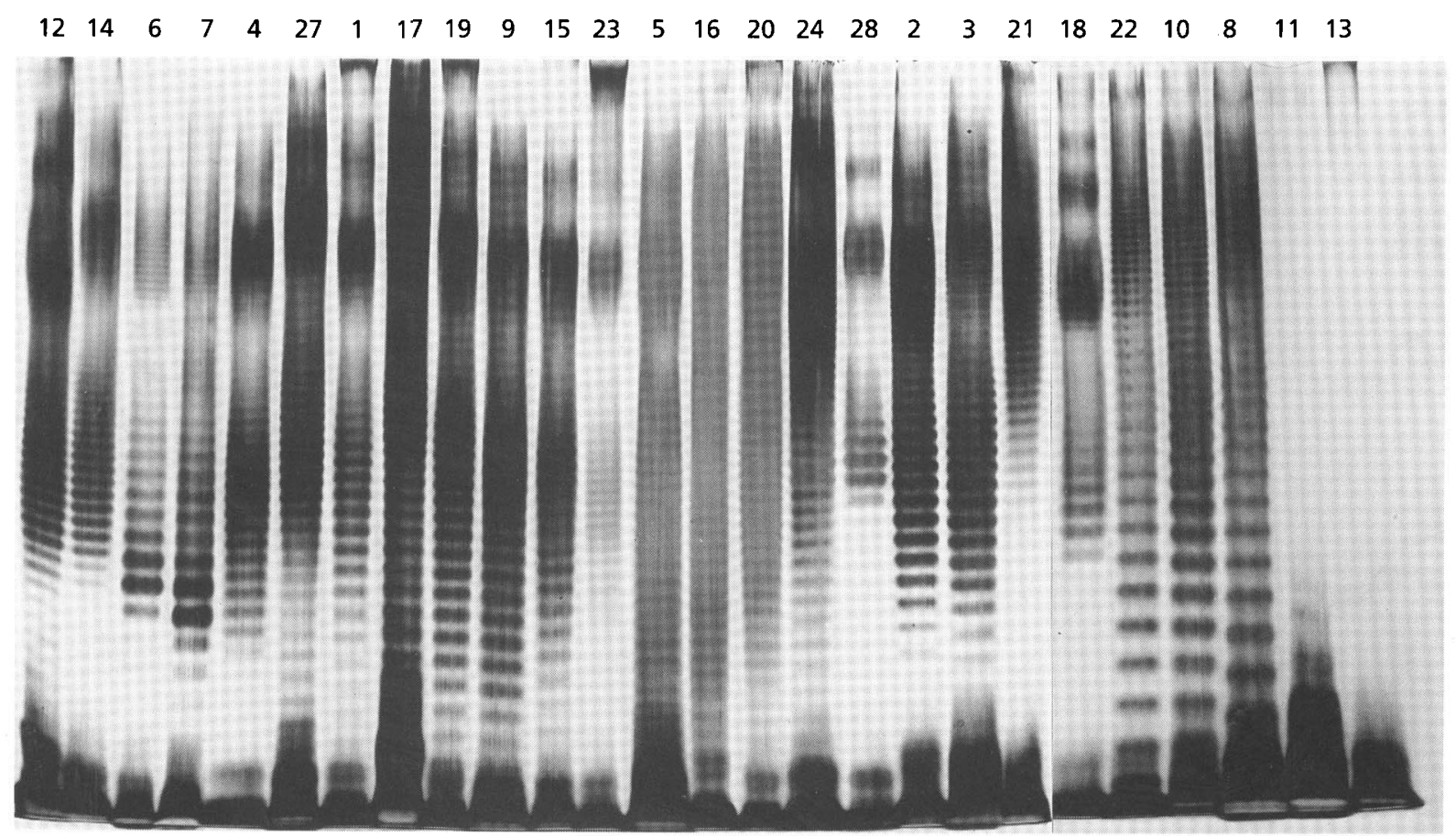

Fig. 1. LPS profiles of the $O$ serotype reference strains of $S$. marcescens.

Table 6. Effect of different S. marcescens antigens and serum adsorptions in ELISA

Tests were performed in duplicate and the mean $\mathrm{OD}_{405}$ coded as $>0 \cdot 9=3,>0 \cdot 6=2,>0 \cdot 4=1$; - no reaction; ads, adsorbed with.

\begin{tabular}{|c|c|c|c|c|c|c|c|c|c|c|}
\hline \multirow[t]{2}{*}{$\begin{array}{l}\text { Original serotype } \\
\text { (new serotype) }\end{array}$} & \multicolumn{5}{|c|}{$\begin{array}{l}\text { TSB antigen (O-ELISA) } \\
\text { Serum }\end{array}$} & \multicolumn{5}{|c|}{$\begin{array}{c}\text { KA antigen (K-ELISA) } \\
\text { Serum }\end{array}$} \\
\hline & $\begin{array}{c}\mathrm{O} 6 \\
\text { adsO14 }\end{array}$ & $\begin{array}{c}\mathrm{O} 14 \\
\text { adsO6 }\end{array}$ & $\begin{array}{l}\text { O7 } \\
\text { ads }^{*}\end{array}$ & $\begin{array}{c}\mathrm{O} 14 \\
\text { adsO12 }\end{array}$ & $\begin{array}{c}\mathrm{O} 12 \\
\text { adsO14 }\end{array}$ & $\begin{array}{c}\mathrm{O} 6 \\
\text { adsO14 }\end{array}$ & $\begin{array}{c}\mathrm{O} 14 \\
\text { adsO6 }\end{array}$ & $\begin{array}{l}\text { O7 } \\
\mathrm{ads}^{*}\end{array}$ & $\begin{array}{c}\mathrm{O} 14 \\
\text { adsO12 }\end{array}$ & $\begin{array}{c}\mathrm{O} 12 \\
\text { adsO14 }\end{array}$ \\
\hline O6 (O6:K14) & 3 & 1 & 3 & - & - & 2 & 1 & - & 2 & - \\
\hline O7 (O6:K7) & 3 & - & 3 & - & - & 2 & - & 3 & - & - \\
\hline O12 (O14:K12) & - & 3 & - & 1 & 3 & - & - & - & - & 3 \\
\hline O14 (O14:K14) & - & 3 & - & 1 & 1 & 2 & 2 & - & 3 & - \\
\hline Antigens detected & O6 & O14 & O6 & O14 & $\mathrm{O} 14$ & $\mathrm{O} 6+\mathrm{K} 14$ & K14 & K7 & K14 & $\mathrm{K} 12$ \\
\hline
\end{tabular}

*843-57-1, acapsular variant of reference strain 843-57 (O7:K7).

indistinguishable from those of proteinase $\mathrm{K}$ extracts (not shown) in all cases. This included the reference strains O2, O3 and O21, for which LPS had been recovered from the phenolic phase of the Westphal extraction. All strains from which a neutral polysaccharide was isolated showed characteristic $\mathrm{O}$ antigen ladders of smooth LPS. The three reference strains deficient in neutral polysaccharide, $\mathrm{O} 11, \mathrm{O} 13$ and $\mathrm{O} 25$, contained only rough LPS. Reference strains possessing the same neutral polysaccharide showed identical or very similar profiles, namely $\mathrm{O} 2$ and $\mathrm{O} 3, \mathrm{O} 6$ and $\mathrm{O} 7$, $\mathrm{O} 12$ and $\mathrm{O} 14, \mathrm{O} 15$ and $\mathrm{O} 26, \mathrm{O} 16$ and $\mathrm{O} 20$, and $\mathrm{O} 17$ and O19. These results were confirmed by immunoblotting. Unadsorbed antisera to reference strains O11, O13 and
O25 revealed only rough LPS profiles while identical profiles were obtained for each of the six pairs above when antiserum to either one of the pair was used for detection. Serum raised against strains sharing identical or related acidic polysaccharides either failed to produce ladder profiles (e.g. serum O14 with reference strain O6, serum $\mathrm{O} 28$ with strains $\mathrm{O} 5$ and $\mathrm{O} 23$ ) or produced a profile different from that of the homologous strain (e.g. serum $\mathrm{O} 6$ on reference strain $\mathrm{O} 14$, serum $\mathrm{O} 5$ on $\mathrm{O} 28$ ).

\section{$O$ and $K$ antigens in ELISA}

Assays were required which could be used for the identification of $\mathrm{O}$ and $\mathrm{K}$ antigens in a routine typing 
laboratory, thus it was necessary to use crude antigen extracts as coating antigens to obviate the need for costly and time-consuming polysaccharide purification of clinical isolates. Reference strains $\mathrm{O} 6, \mathrm{O} 7, \mathrm{O} 12$ and $\mathrm{O} 14$ have only two $\mathrm{O}$ antigens and three $\mathrm{K}$ antigens between them and were therefore used to develop $\mathrm{O}$ and $\mathrm{K}$-specific ELISAs. The coating antigens were, respectively, whole cells grown in tryptone soya broth then autoclaved to reduce the amount of capsular material present (Gaston et al., 1988) and formolized whole cells grown on $\mathrm{KA}$ to maximize capsule production. Cross-adsorptions of the four sera to eliminate either anti-O or anti-K antibodies were carried out using the reference strains with matching $\mathrm{O}$ or $\mathrm{K}$ antigens, respectively, except for the anti-K 7 reagent which was prepared by adsorption with an acapsular variant (84357-1) of the $\mathrm{O} 7$ reference strain. The resulting reagents were tested in both ELISAs and the results are shown in Table 6 . They indicate that both appropriate adsorption and an appropriate coating antigen are required for specific antigen detection. For example, the system which best detected the $\mathrm{O}$ antigen of reference strains $\mathrm{O} 12$ (O14:K12) and O14 (O14:K14) was serum O14 adsorbed with reference strain O6 (O6:K14) in the OELISA. Detection of the K14 antigen with this serum required adsorption with reference strain $\mathrm{O} 12$ (O14: K12) and use of the K-ELISA.

\section{0 antigen typing scheme}

Use of unadsorbed sera in the O-ELISA produced numerous cross-reactions (Table 7), many of which could be ascribed to shared polysaccharides. To produce specific reagents for $\mathrm{O}$ serotyping based on the neutral polysaccharide structures alone, all $\mathrm{O}$ antisera were adsorbed with antigens chosen to minimize the crossreactions predicted from their chemical structures. These sera were tested at their working concentrations against all reference strains in the O-ELISA. None of them gave non-specific background readings and, other than those due to shared $\mathrm{O}$ antigens, there was only one significant cross-reaction: serum $\mathrm{O} 14$ with reference strain $\mathrm{O} 23$ (O23:K23) which was not investigated further. These reagents were likewise shown to be Oantigen-specific by immunoblotting.

Preliminary experiments suggested that purified neutral and acidic polysaccharides did not bind well to ELISA plates so, unfortunately, could not be used in these adsorbed antisera assays to demonstrate directly the correlation of chemical structure with serological specificity. The separated polysaccharides were used in a number of immunoassays, namely inhibition of purified LPS-mediated indirect haemagglutination, double diffusion and indirect capture ELISA, in an attempt to obtain such data but with only partial success. For each assay, those positive results which were obtained could be easily explained by reference to the chemical structures. For example, the $12 \mathrm{~N}$ (neutral polysaccharide from reference strain $\mathrm{O} 12), 14 \mathrm{~N}$ and $14 \mathrm{~A}$ polysaccharides reacted with immunoglobulin purified from (unadsorbed) O14 antiserum in the capture ELISA, whereas $7 \mathrm{~N}, 7 \mathrm{~A}$ and $12 \mathrm{~A}$ did not $(6 \mathrm{~N}$ and $6 \mathrm{~A}$ were not available). However, many reactions predicted by chemistry did not occur, e.g. the immunoglobulin purified from (unadsorbed) O12 antiserum failed to bind any of the separated polysaccharides, although strong positive reactions were seen with the purified LPS from reference strains $\mathrm{O} 12$ and $\mathrm{O} 14$, but not with $\mathrm{O} 6$ or O7. Further work is needed in this area but it is possible that removal of lipid A from the polysaccharides alters their conformation so that they are less immunoreactive.

The O-ELISA was used to determine the O serotypes of 423 clinical strains to assess assay specificity: serotype frequencies will be published elsewhere. Representatives of all serotypes were tested by immunoblotting to confirm their $\mathrm{O}$ antigen and to check serotype homogeneity. Seventy-nine cross-reactions occurred but 36 of these were weak and did not prevent the correct identification of $\mathrm{O}$ serotype. Thirty-three strains reacted with either the $\mathrm{O} 4, \mathrm{O} 23$ or $\mathrm{O} 28$ reagents in addition to those identifying their true $\mathrm{O}$ serotypes. These reactions were shown to be due to capsular antigens and could be eliminated by the use of alternative reagents (see below). Eight strains reacted with both the $\mathbf{O} 16$ and $\mathrm{O} 20$ reagents but as immunoblotting confirmed that they possessed both antigens, as does the O16 reference strain, this cross-reaction must be considered justified. The remaining two strains reacted with both $\mathrm{O} 4$ and $\mathrm{O} 14$ reagents and were identified as O4:K14 strains. Since the other $253 \mathrm{~K} 14$ strains did not show this crossreaction, which could in any case be readily investigated by Quellung, modification of the $\mathrm{O} 14$ reagent was considered unnecessary. Thus the final $\mathrm{O}$ antigen adsorption scheme, as shown in Table 2 , produced only two $(0.5 \%)$ non-specific results among the 423 strains.

Taken together, the chemical and serological results delineated eight structurally and serologically related groups of $\mathrm{O}$ serotypes, which are described in more detail below.

\section{Group I}

Each of the seven reference strains in this group has a disaccharide repeating unit consisting of a rhamnose residue with $\mathrm{N}$-acetylglucosamine (O1, O17 and $\mathrm{O} 19)$ or $\mathrm{N}$-acetylgalactosamine (O9, O15, O23, O26). Strain $\mathrm{O} 23$ was the only member of the group to produce a clearly distinct LPS profile (Fig. 1) and no serological cross-reactions among the other type strains in the group by either ELISA or immunoblotting with unadsorbed sera. However, serum O23 required adsorption with an O28: K23 clinical strain, S4093, to eliminate cross-reacting K23 antibodies.

Reference strains O9, O15 and O26 possess two linkage variants of the same disaccharide in different proportions; in $\mathrm{O} 9$ the $(1 \rightarrow 3)$-linked rhamnose- $\mathrm{N}$-acetylgalactosamine predominates while in strains $\mathrm{O} 15$ and O26 the $(1 \rightarrow 4)$-linked disaccharide is the major form. Consequently, it was not surprising that cross-reactions between these three strains occurred and that their LPS 
Table 7. Serological reactions of the 290 serotype reference strains of $S$. marcescens in the O-ELISA

Tests were performed on three separate occasions and the mean OD coded as $>0 \cdot 9=3,>0 \cdot 6=2,>0 \cdot 4=1$. Results underlined are those obtained using the adsorbed sera listed in Table 3.

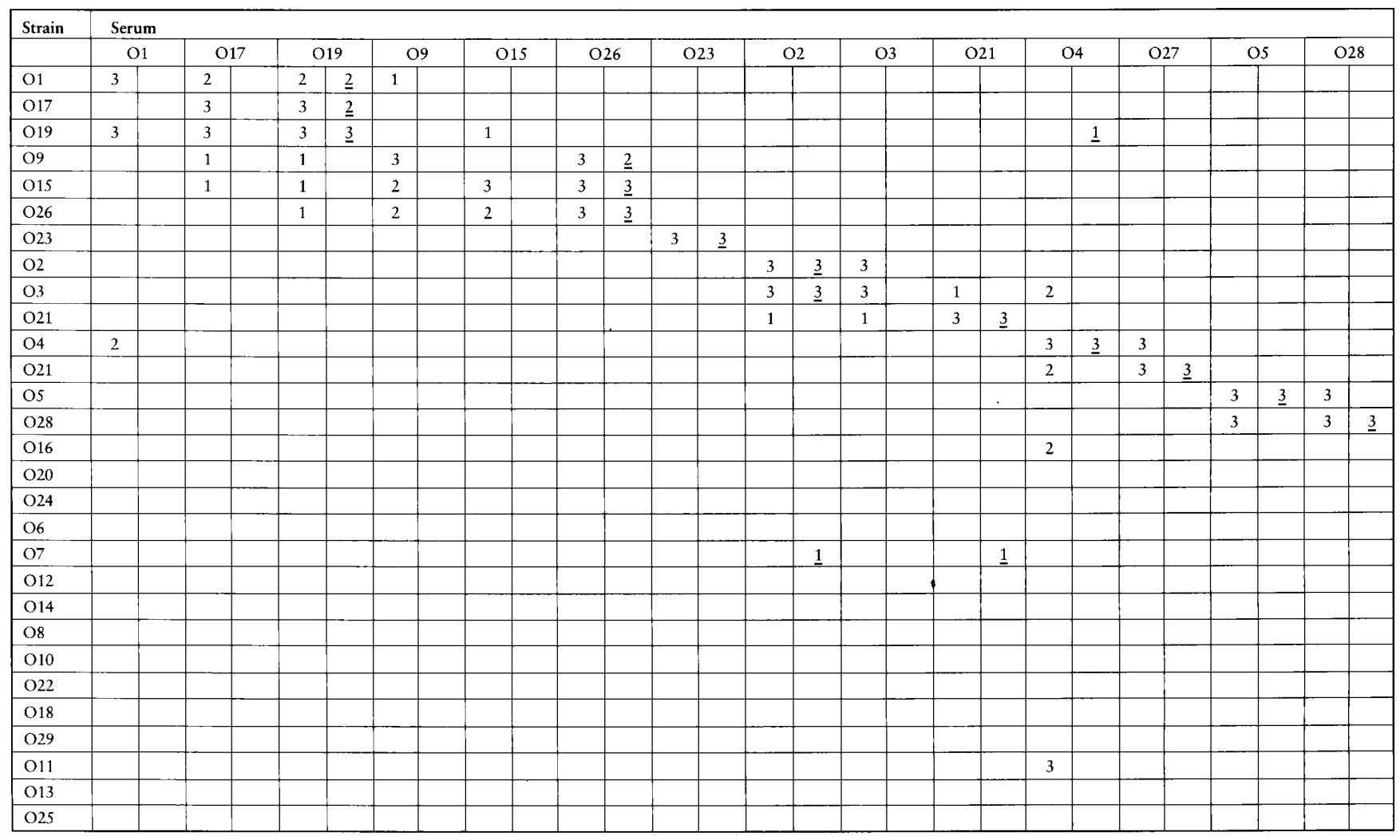

profiles were indistinguishable by silver staining and immunoblotting. Thus, no attempt was made to differentiate between them in the revised typing scheme. Cross-reactions occurred between all three of these strains when tested with unadsorbed $\mathrm{O} 17$ and O19 sera, although the reverse was much less common. Strains $\mathrm{O} 17$ and $\mathrm{O} 19$ have $\mathrm{N}$-acetylglucosamine as their second sugar, not $N$-acetylgalactosamine, but this difference is presumably less significant immunologically than, for example, the second $(1 \rightarrow 4)$-linkage of $\mathrm{O} 23$. The $\mathrm{O} 26$ reference strain was chosen to represent this serotype since it is acapsular and the $\mathrm{O} 26$ antiserum was adsorbed with O19 to remove cross-reactions. In both ELISA and immunoblotting, this reagent was shown to be specific for strains O9, O15 and O26.

The neutral polysaccharides of $\mathrm{O} 17$ and $\mathrm{O} 19$ are identical, as were their SDS-PAGE profiles, and there were strong reciprocal cross-reactions between them. The only difference between this neutral polysaccharide and that of $\mathrm{O} 1$ was the absence from the latter of any (1 $\rightarrow 3$ )-linked rhamnose. This difference proved to be insufficient to allow complete serological differentiation of these strains and as only five representatives were found among the clinical strains, they were considered as one, with the non-capsular O19 as the serotype strain and $\mathrm{O} 9$ as the adsorbing strain.

\section{Group II}

Reference strains $\mathrm{O} 2$ and $\mathrm{O} 3$ have the same neutral disaccharide repeating unit which differs from that of $\mathrm{O} 21$ only in its possession of an $\mathrm{N}$-acetyl group. It was anticipated, therefore, that cross-reactions would occur among these three strains. However, although reference strains $\mathrm{O} 2$ and $\mathrm{O} 3$ showed strong reciprocal reactions, the reactions with unadsorbed serum O21 were generally weaker, suggesting that they are serologically distinguished by the $\mathrm{N}$-acetyl group. This was borne out with adsorbed antisera; serum $\mathrm{O} 2$ adsorbed with reference strain $\mathrm{O} 21$ detected only the $\mathrm{O}$ antigen of reference strains $\mathrm{O} 2$ and $\mathrm{O} 3$ in ELISA and immunoblotting, while serum $\mathrm{O} 21$ adsorbed with reference strains $\mathrm{O} 2$ and $\mathrm{O} 3$ reacted only with strain O21, as shown in Fig. 2. Furthermore, the O21 LPS profile was significantly different from that of $\mathrm{O} 2$ and O3. Serum O21 did not require further adsorption since the reference strain is acapsular, but serum $\mathrm{O} 2$ was improved by adsorption with S117, an O19:K2 clinical strain, to remove antiK2 antibodies.

\section{Group III}

As was shown in the study describing the O27 serotype strain (Aucken et al., 1996), the neutral polysaccharides 
Table 7. (cont.)

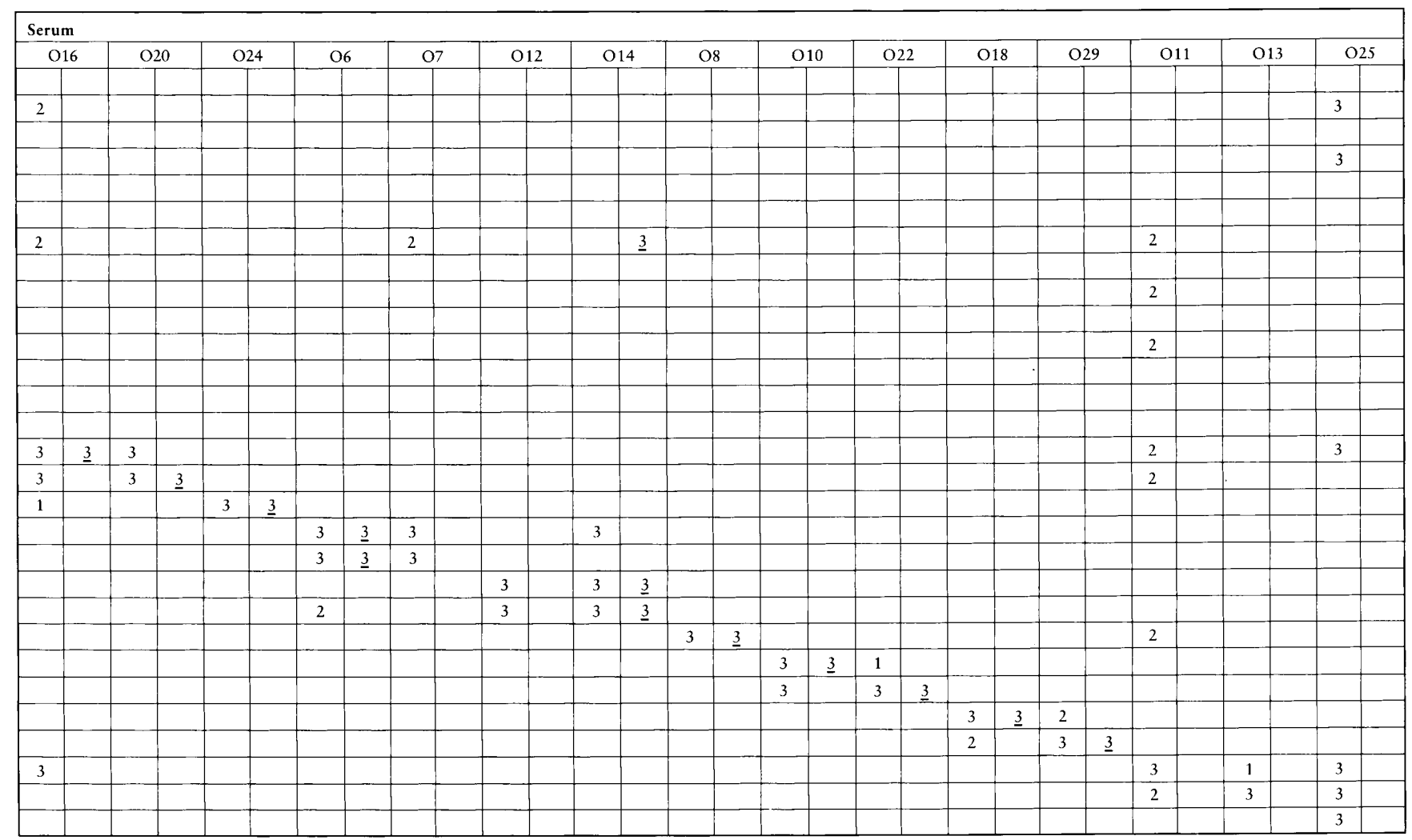

of $\mathrm{O} 4$ and $\mathrm{O} 27$ differ only slightly in chemical structure: the $\mathrm{O} 4$ disaccharide is $\mathrm{O}$-acetylated. In addition, they differ from that of reference strains $\mathrm{O} 6$ and $\mathrm{O} 7$ in having an $\alpha$-rather than $\beta$-linked rhamnose. Immunologically, the difference between the $\alpha$ and $\beta$ linkages seems to be highly significant, since no unadsorbed serum crossreactions were found between reference strains $\mathrm{O} 4$ or $\mathrm{O} 27$ and either $\mathrm{O} 6$ or O7. The repeating unit structures of $\mathrm{O} 4$ and $\mathrm{O} 27$ differed only in an $\mathrm{O}$-acetyl group, present on the former but not the latter, yet their crossreactions could be eliminated completely with adsorbed sera in both O-ELISA and immunoblotting. The silverstained LPS profiles of reference strains $\mathrm{O} 4$ and $\mathrm{O} 27$ were correspondingly similar but not identical (Fig. 1). Immunoblotting of clinical strains showed that the $\mathrm{O} 4$ serum also required adsorption with the $\mathrm{O}-: \mathrm{K} 4$ clinical strain, S1725, before it was truly O-specific (Aucken et al., 1996) but once this was done there were no difficulties in assigning the two types within the collection of $S$. marcescens strains.

\section{Group IV}

The $\mathrm{O}$ antigen of reference strain $\mathrm{O} 24$ contains the same disaccharide backbone as that found in the repeating unit shared by reference strains $\mathrm{O} 16$ and $\mathrm{O} 20$ but differs in having an extra galactose residue so that its repeating unit is a branched trisaccharide. This results in a tertiary structure with sufficient differences to prevent marked serological cross-reactions. Weak reactions were noted only between serum O16 and strain O24 in the unadsorbed serum O-ELISA and the latter may well have been non-specific, given that serum O16 produced high background readings in this assay. Since the O24 reference strain is acapsular and serum O24 did not cross-react with any of the reference strains, it could be used without adsorption. However, for consistency, O14 was used as an adsorbing strain when no others were required. As with other groups of strains, minimal serological cross-reaction was correlated with differences in their LPS profiles. Thus, although the SDSPAGE ladders of reference strains O16 and O20 were relatively similar, that of the non-cross-reacting $\mathrm{O} 24$ was clearly distinguishable. Strains $\mathrm{O} 16$ and $\mathrm{O} 20$ have the same disaccharide repeating unit, but $\mathrm{O} 16$ also produces a second neutral polysaccharide with a monomeric repeating unit (Table 4). As expected, therefore, these two strains showed strong cross-reactions in ELISA and when immunoblotted with unadsorbed antisera. Adsorption of serum O16 with reference strain $\mathrm{O} 20$ generated a specific reagent, while strain O14 was used with serum O20. Interestingly, both unadsorbed and adsorbed $\mathrm{O} 20$ sera revealed a ladder pattern when 
(a)

(b)

$2 \quad 3 \quad 21$

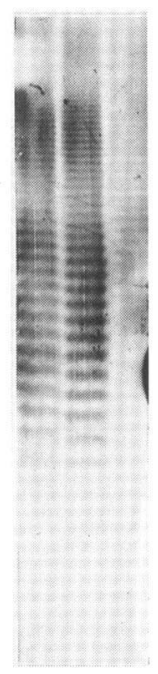

(c)

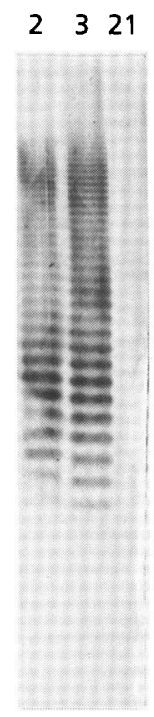

(d)

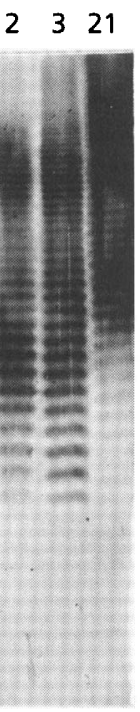

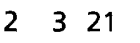

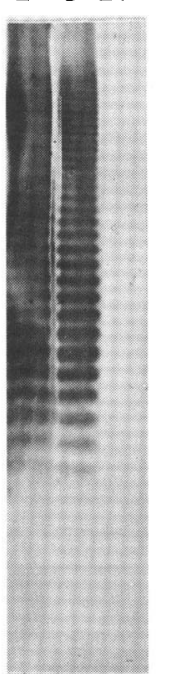

(e)
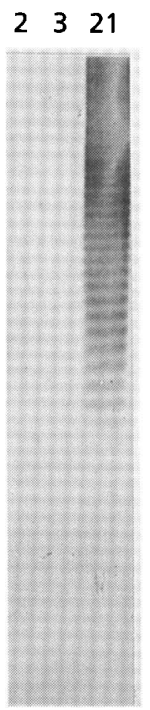

Fig. 2. Immunoblotting results of the $\mathrm{O} 2$ (O2: K2), $\mathrm{O} 3(\mathrm{O2}: \mathrm{K3})$ and $\mathrm{O} 21(021: \mathrm{K}-)$ serotype reference strains of $S$. marcescens with (a) serum O2, (b) serum O3, (c) serum O21, (d) serum $\mathrm{O} 2$ adsorbed with $\mathrm{O} 21$ and (e) serum $\mathrm{O} 21$ adsorbed with $\mathrm{O} 2$ and O3.

used to immunoblot strain O28. The explanation for this reaction remains unclear since the $\mathrm{O}$-antigenic repeating unit of $\mathrm{O} 28$ is mannose trisaccharide, whereas that of $\mathrm{O} 20$ is a galactose disaccharide. However, since this cross-reaction did not occur in the O-ELISA, it did not give any problems for serotyping. Both types were rare in the clinical collection and no strains were found with the O16 antigen alone. Consequently, for the purposes of routine epidemiological typing, it would seem both economical and practical to use unadsorbed O16 serum for the detection of $\mathrm{O} 16$ and $\mathrm{O} 20$ antigens as a combined $\mathrm{O} 16 / \mathrm{O} 20$ serotype.

Despite the similarities between the O16/O20 and O5 neutral polysaccharides, no cross-reactions occurred between them. The LPS profile of reference strain O5 was slightly different from others in this group (Fig. 1). Marked cross-reactions did occur, however, between reference strains $\mathrm{O} 5$ and $\mathrm{O} 28$. This cross-reaction was investigated in a previous study (Aucken et al., 1996) and shown to be due to similarities in their acidic capsular polysaccharides. Both O5 and O28 sera could be made specific in immunoblotting by cross-adsorption, although serum $\mathrm{O} 28$ adsorbed with strain $\mathrm{O} 5$ continued to react with strain O5 in the ELISA. Adsorptions of the original serum with a variety of non-O28:K28 strains also failed to produce an O28-specific reagent, suggesting that cross-reacting $\mathrm{K}$ antibodies still remained after adsorption. Sera raised to the acapsular variants or clinical strains used in the $\mathrm{K}$ adsorption scheme would circumvent the problem of $\mathrm{K}$ antibody adsorption and this approach has now been successfully used to prepare a new rabbit antiserum which is a fully specific $\mathbf{O} 28$ serotyping reagent.

\section{Group V}

Only two neutral polysaccharides have been identified among reference strains $\mathrm{O} 6, \mathrm{O} 7, \mathrm{O} 12$ and $\mathrm{O} 14$ : one shared by $\mathrm{O} 6$ and $\mathrm{O} 7$ and the other by $\mathrm{O} 12$ and $\mathrm{O} 14$. In addition, strains $\mathrm{O} 6$ and $\mathrm{O} 14$ share the same acidic polysaccharide, whereas $\mathrm{O} 7$ and $\mathrm{O} 12$ have different capsular polysaccharides. The SDS-PAGE results correlated with neutral polysaccharide structures, with $\mathrm{O} 6$ and O7 having the same LPS profile, which was clearly distinct from that shared by $\mathrm{O} 12$ and O14 (Fig. 1). Unadsorbed serum ELISA results accurately reflected the distribution of these structures; reciprocal crossreactions were seen between reference strains $\mathrm{O} 6$ and $\mathrm{O} 7$ as well as between $\mathrm{O} 12$ and O14. Furthermore, serum $\mathrm{O} 6$ reacted with reference strain O14. However, some slightly anomalous results were obtained by immunoblotting. Although those strains with identical neutral polysaccharide structures clearly had the same LPS profile, a ladder pattern was also developed by serum $\mathrm{O} 6$ on strain $\mathrm{O} 14$ and even more surprisingly on strain O12. Adsorption of serum O6 with strain O14 and vice versa eliminated these reactions in both immunoblotting and ELISA, apart from the two O4:K14 clinical strains mentioned above which reacted with the $\mathrm{O} 14$ as well as the $\mathrm{O} 4$ reagent.

\section{Group VI}

The detection of the $\mathrm{O} 8$ antigen posed no problems, since the reference strain is acapsular and the neutral polysaccharide has a unique SDS-PAGE profile. This polymer has also been found together with the acidic glucorhamnan of reference strains O6 and O14 (see below) in a strain previously considered to be 'O14' (Brigden \& Wilkinson, 1985b).

\section{Group VII}

The repeating unit structures of reference strains O10, $\mathrm{O} 18, \mathrm{O} 22$ and $\mathrm{O} 29$ are all based on a backbone of one glucose or $\mathrm{N}$-acetylglucosamine and three rhamnose residues. In strains $\mathrm{O} 10$ and $\mathrm{O} 22$, these sugars are joined by two $(1 \rightarrow 2)$ - and two $(1 \rightarrow 3)$-linkages, whereas $\mathrm{O} 18$ and O29 have three $(1 \rightarrow 2)$ - and one $(1 \rightarrow 6)$-linkage instead. The neutral polysaccharide of reference strain O10 differs from that of $\mathrm{O} 22$ in having an additional, lateral glucose residue, while $\mathrm{O} 29$ has a glucose residue rather than the $\mathrm{N}$-acetylglucosamine of O18. Results with the unadsorbed antisera showed that the differences in linkages seem to have more influence on tertiary structure than does the presence of the side-group. Not only were the profiles of reference strains $\mathrm{O} 10$ and $\mathrm{O} 22$ very similar in SDS-PAGE and that of O18 and O29 quite different, but cross-reactions in ELISA and immunoblotting only occurred within and not between each pair.

Adsorption of serum $\mathrm{O} 22$ with both reference strain $\mathrm{O} 10$ and the $\mathrm{O}-: \mathbf{K} 22$ clinical strain, S2164, produced an $\mathrm{O}$-specific reagent, but adsorption of serum $\mathrm{O} 10$ with strain $\mathrm{O} 22$ still left some residual cross-reactivity with 
both reference strain $\mathrm{O} 22$ and the clinical $\mathrm{O} 22$ strains. The significant structural difference between the two antigens was considered sufficient to justify their inclusion in the scheme as distinct types, but, since both types were rare in the clinical collection, for routine epidemiological typing it seems reasonable to detect them together as $\mathrm{O} 10 / \mathrm{O} 22$ using unabsorbed $\mathrm{O} 10$ serum.

Unfortunately, no O18-negative but K18-positive strain was identified among the clinical collection with which to render serum O18 O-specific by adsorption of $\mathrm{K} 18$ antibodies. At the time the clinical collection was tested, reference strain O29 had not been described and three ' $\mathrm{O} 18$ ' strains were found and confirmed by immunoblotting. Further testing by ELISA and immunoblotting with cross-adsorbed O18 and O29 sera showed that only one of these strains was $\mathrm{O} 18$, as were two of nine identified subsequently. The others were all O29. Thus, as has been suggested before with infrequent serotypes, the requirements of normal epidemiological typing would be satisfied by detection of a combined O18/O29 antigen using $\mathrm{O} 29$ serum adsorbed with reference strain $\mathrm{O} 4$ to remove $\mathrm{K} 4$ antibodies.

\section{Group VIII}

Chemical analysis failed to detect any neutral polysaccharide in reference strains O11, O13 and O25 and they were shown by SDS-PAGE to be rough strains lacking $\mathrm{O}$ antigen. Both whole-cell ELISA and immunoblotting with unadsorbed O11, O13 and O26 sera revealed cross-reactions between these three strains as well as with other reference strains. Immunoblotting confirmed that these were due to core or lipid A determinants on rough LPS. All three were non-typable in the O typing ELISA as they were negative with all the adsorbed antisera.

\section{K typing scheme}

An earlier study had identified 14 different $\mathrm{K}$ antigens among serotype strains $\mathrm{O} 1-\mathrm{O} 28$ of $S$. marcescens (Aucken et al., 1997). Twelve of these were each found in only one of the serotype strains and cross-reacting $\mathrm{O}$ antibodies were adsorbed from the corresponding sera using either acapsular variants of the homologous strains or heterologous strains of the same $\mathrm{O}$ type (Table $3)$. Thus, adsorbed antisera to 8 of the 12 antigens were prepared using the phage-resistant acapsular variants described previously (Aucken et al., 1997) which had been grown on NA to minimize any residual capsule production. Serum O12 was adsorbed by reference strain O14 since these two strains have identical $\mathrm{O}$ antigen structures, while serum $\mathrm{O} 22$ was adsorbed with strain $\mathrm{O} 10$ as an O22: non-K22 strain was not available and the $\mathrm{O}$ antigen repeating units of reference strains $\mathrm{O} 10$ and $\mathrm{O} 22$ are serologically very similar. Serum $\mathrm{O} 18$ was adsorbed with an O29:K4 clinical strain, S1072, as no O18:non-K18 was available, while serum O13 was adsorbed with strain O11 to remove rough LPS antibodies.
The $\mathrm{O} 6$ and $\mathrm{O} 14$ reference strains had chemically and serologically indistinguishable capsules and $\mathrm{O} 14$ was chosen as the $\mathrm{K}$ serotype strain since historically this has been the most frequent serotype among clinical $S$. marcescens isolates (Gaston \& Pitt, 1989b; Le Minor \& Pigache, 1978; Pitt et al., 1980; Rubin et al., 1976). A Kspecific typing reagent was prepared by adsorption of serum O14 with strain O12. The fourteenth antigen is represented in the scheme by reference strain $\mathrm{O} 28$ (O28: K28). Although the acidic polysaccharide repeating units of the $\mathrm{O} 5$ and $\mathrm{O} 28$ reference strains are chemically distinct, it proved impossible to distinguish them serologically (Aucken et al., 1997), suggesting their shared amino sugar side-group is an immunodominant determinant. A putative fifteenth $\mathrm{K}$ antigen was the acidic polysaccharide identified in reference strain $\mathrm{O} 11$. However, because it has not been possible to detect a capsule around this strain either directly with Indian ink or Quellung reaction, or indirectly by precipitation with Cetavlon, it has been excluded from the scheme (Aucken et al., 1997).

In the K-ELISA, each of the 14 homologous reactions was distinct and gave acceptable OD levels, as did all the cross-reactions predicted from the chemical and immunological analyses, namely those between the two pairs of reference strains, $\mathrm{O} 6$ and $\mathrm{O} 14$ plus $\mathrm{O} 5$ and $\mathrm{O} 28$. There were 11 unforeseen cross-reactions but as all were weak and tended to be associated with individual strains producing higher background OD levels with all sera $(0 \cdot 3$ rather than $0 \cdot 15)$, they were not expected to interfere with $\mathrm{K}$ type determination.

$\mathrm{K}$ typing ELISA plates were prepared from the 423 clinical strains and tested with the adsorbed K sera. All weak results and cross-reactions were checked with the Quellung test and so were all non-K14 results. Five strains $(1 \%)$ produced cross-reactions which fell into two groups. One group consisted of three strains which reacted with both $\mathbf{K 2 2}$ and $\mathbf{2 3}$ reagents with or without an additional K13 reaction. Quellung tests showed strong reactions with reagent $K 22$ in two cases and K13 in the third, although faint, wide halos were seen with the other reagents. There is no obvious structural similarity among these three $\mathrm{K}$ antigens and the reason for the cross-reaction remains obscure. The second group of cross-reactions involved two strains which reacted with both the K3 and K15 reagents. Quellung tests identified them as K3 strains, although again, faint, wide halos could be seen with the second serum. Since $\mathrm{K3}$ was one of the more frequent serotypes, this crossreaction was investigated further. Fourteen other K3 strains were tested and all but three produced faint but clear halos in the Quellung reaction with reagent $\mathrm{K15}$, including the $\mathrm{O} 3(\mathbf{O} 2: \mathbf{K 3})$ reference strain. The O15 $\langle\mathrm{O} 15: \mathrm{K} 15\rangle$ strain gave a negative Quellung reaction with the $\mathbf{K} 3$ reagent, whereas faint halos were seen with the two K15 clinical strains. The K3 and K15 antigens have similar sugars in a tetrasaccharide repeating unit with a mannose side-chain. However, there are many differences in the linkages which could account for the serological distinction. Structural analysis of the poly- 
saccharides of the clinical strains would be required to test this hypothesis.

\section{Conclusions}

Table 1 lists the 29 reference strains so far described as O serotype strains, together with their new serotype designations, each of which now represents a chemically defined repeating unit structure. Nineteen strains have been retained as serotype strains in the revised $\mathrm{O}$ typing scheme (Table 2) while 14 strains make up the K typing scheme (Table 3). Seven reference strains appear in both lists which leaves three strains not appearing in either of the new typing schemes; these are O11, O17 and O25. Reference strain O11 is an atypical strain of $S$. marcescens. It grows abnormally slowly and the individual cells are abnormally long, suggestive of some defect in the cell division process. It is possible that the capsule is present but in quantities too small to be detected by light microscopy. Alternatively, it could be a strain which bears the enterobacterial common antigen in an immunogenic state, although there is no evidence of its presence in any of the isolated polysaccharides. Reference strain $\mathrm{O} 17$ is acapsular and shares an $\mathrm{O}$ antigen with strain O19 which was chosen as the serotype representative, while strain $\mathrm{O} 25$ is both acapsular and $\mathrm{O}$-antigen-deficient, suggesting that other determinants must be responsible for the original serotype specificities of these two strains.

Both $\mathrm{O}$ and $\mathrm{K}$ typing schemes have been in routine use at the Central Public Health Laboratory for over 4 years, allowing confident allocation of serotypes in the majority of cares. Cross-reactions are rare and when they do occur can usually be resolved using the Quellung reaction.

\section{REFERENCES}

Aucken, H. M. \& Pitt, T. L. (1993). Lipopolysaccharide profile typing as a technique for the comparative typing of Gramnegative bacteria. J Clin Microbiol 31, 1286-1289.

Aucken, H. M., Merkouroglou, M., Miller, A. W., Galbraith, L. \& Wilkinson, S. G. (1995). Structural and serological studies of lipopolysaccharides from proposed new serotypes (O25 and O26) of Serratia marcescens. FEMS Microbiol Lett 130, 267-272.

Aucken, H. M., Wilkinson, S. G. \& Pitt, T. L. (1996). Immunochemical characterisation of two new O serotypes of Serratia marcescens (O27 and O28). FEMS Microbiol Lett 138, 77-82.

Aucken, H. M., Wilkinson, S. G. \& Pitt, T. L. (1997). Identification of capsular antigens in Serratia marcescens. J Clin Microbiol 35, $59-63$

Brigden, C. J. \& Wilkinson, S. G. (1983). Lipopolysaccharide from the O14 type strain of Serratia marcescens: structural studies of a polymeric fraction. Carbobydr Res 115, 183-190.

Brigden, C. J. \& Wilkinson, S. G. (1985a). Structural studies of acidic glucomannans from strains of Serratia marcescens O14 and O6. Carbohydr Res 138, 267-276.

Brigden, C. J. \& Wilkinson, S. G. (1985b). Structural studies of a neutral polymeric fraction from the lipopolysaccharide of Serratia marcescens CDC 1783-57 (O14: H9). Carbohydr Res 145, 81-87.

Brigden, C. J., Furn, S. \& Wilkinson, S. G. (1985). Structural studies of neutral polymers isolated from the lipopolysaccharides of
Serratia marcescens O6 (strain CDC 862-57) and O12 (CDC 632058). Carbohydr Res 139, 298-301.

Davis, B. R. \& Woodward, J. M. (1957). Some relationships of the somatic antigens of a group of Serratia marcescens cultures. Can J Microbiol 3, 591-597.

Ewing, W. H., Davis, B. R. \& Reavis, R. W. (1959). Studies on the Serratia Group. Atlanta, GA: Centers for Disease Control.

Ewing, W. H., Johnson, J. G. \& Davis, B. R. (1962). The Occurrence of Serratia marcescens in Nosocomial Infections. Atlanta, GA: Centers for Disease Control.

Farmer, J. J., III, Davis, B. R., Hickman, F. W., Presley, D. B., Bodey, G. P., Negut, M. \& Bobo, R. A. (1976). Detection of Serratia outbreaks in hospital. Lancet 2, 455-459.

Furn, S. \& Wilkinson, S. G. (1985). Structure of a neutral polymer isolated from the lipopolysaccharide of Serratia marcescens O1 (strain CDC 866-57). Carbohydr Res 139, 293-297.

Gaston, M. A. \& Pitt, T. L. (1989a). O-antigen specificities of the serotype strains of Serratia marcescens. J Clin Microbiol 27, 2697-2701.

Gaston, M. A. \& Pitt, T. L. (1989b). Improved O-serotyping method for Serratia marcescens. J Clin Microbiol 27, 2702-2705.

Gaston, M. A., Duff, P. S. \& Pitt, T. L. (1988). Lipopolysaccharide heterogeneity in strains of Serratia marcescens agglutinated by O14 antiserum. Curr Microbiol 17, 27-31.

Hitchcock, P. J. \& Brown, T. M. (1983). Morphological heterogeneity among Salmonella lipopolysaccharide chemotypes in silver-stained polyacrylamide gels. J Bacteriol 154, 269-277.

Holst, O., Aucken, H. M. \& Seltmann, G. (1997). Structural and serological characterisation of the O-specific polysaccharide of the lipopolysaccharide from proposed new serotype O29 of Serratia marcescens. J Endotoxin Res 4, 215-220.

Johansson, A., Widmalm, G., Jansson, P.-E. \& Wilkinson, S. G. (1995). Structure of an acidic microcapsular glycan from the reference strain (CDC 866-57) for Serratia marcescens serogroup O1. Carbobydr Res 270, 191-199.

King, E. O., Ward, M. K. \& Raney, D. E. (1954). Two simple media for the demonstration of pyocyanin and fluorescin. J Lab Clin Med 14, 301-308.

Le Minor, S. \& Pigache, F. (1978). Étude antigénique de souches de Serratia marcescens isolées en France. II. Caractérisation des antigènes $\mathrm{O}$ et individualisation de 5 nouveaux facteurs, fréquence de sérotypes et désignation des nouveaux facteurs $\mathrm{H}$. Ann Inst Pasteur (Paris) 129B, 407-423.

Le Minor, S. \& Sauvageot-Pigache, F. (1981). Nouveaux facteurs antigéniques $\mathrm{H}(\mathrm{H} 21-\mathrm{H} 25)$ et $\mathrm{O}(\mathrm{O} 21)$ de Serratia marcescens, subdivision des facteurs O5, O10, O16. Ann Inst Pasteur (Paris) 132A, 239-252.

Le Minor, S., Benazet, F. \& Martin, L. (1983). Nouveaux facteurs antigéniques $\mathrm{O}(\mathrm{O} 23)$ et $\mathrm{H}$ (H26) de Serratia marcescens. Ann Inst Pasteur (Paris) 134B, 447-449.

Ørskov, F. (1976). Agarose electrophoresis combined with second dimensional Cetavlon precipitation. A new method for demonstration of acidic polysaccharide $\mathrm{K}$ antigens. Acta Path Microbiol Scand B 84, 319-320.

Ørskov, F. \& Ørskov, I. (1992). Escherichia coli serotyping and disease in man and animals. Can J Microbiol 38, 699-704.

Ørskov, I. \& Ørskov, F. (1984). Serotyping of Klebsiella. Methods Microbiol 14, 143-164.

Oxley, D. \& Wilkinson, S. G. (1986). Structure of the O-specific polysaccharide from the lipopolysaccharide of Serratia marcescens O8. Eur J Biochem 156, 597-601. 
Oxley, D. \& Wilkinson, S. G. (1987). Structural studies of the putative O-specific polysaccharide of Serratia marcescens O9. Eur $J$ Biochem 166, 421-424.

Oxley, D. \& Wilkinson, S. G. (1988a). Studies of lipopolysaccharides from two strains (CDC 3607-60 and IP421) of Serratia marcescens $\mathrm{O} 13$, structure of the putative $\mathrm{O} 13$ antigen. Carbobydr Res 172, 275-286.

Oxley, D. \& Wilkinson, S. G. (1988b). Structure of a neutral polymer isolated from the lipopolysaccharide of Serratia marcescens O5 (CDC 867-57). Carbohydr Res 172, 287-291.

Oxley, D. \& Wilkinson, S. G. (1988c). Structural studies of glucorhamnans isolated from the lipopolysaccharides of reference strains for Serratia marcescens serogroups O4 and O7, and of an O14 strain. Carbohydr Res 175, 111-117.

Oxley, D. \& Wilkinson, S. G. (1988d). Structure of a neutral polymer isolated from the lipopolysaccharide of the reference strain (CDC 4523-60) for Serratia marcescens serogroup O15. Carbohydr Res 177, 285-288.

Oxley, D. \& Wilkinson, S. G. (1988e). Structural studies of an acidic galactomannan from the reference strain for Serratia marcescens serogroup O4. Carbohydr Res 179, 341-348.

Oxley, D. \& Wilkinson, S. G. (1988f). Structural studies of an acidic galactorhamnan from the O2 reference strain (CDC 868-57) of Serratia marcescens. Carbohydr Res 182, 101-109.

Oxley, D. \& Wilkinson, S. G. (1989a). Structural studies of an acidic galactoglucomannan from the $\mathrm{O} 15$ reference strain (CDC 4523-60) of Serratia marcescens. Carbohydr Res 186, 295-300.

Oxley, D. \& Wilkinson, S. G. (1989b). Structural studies of an acidic galactoglucomannan from the $\mathrm{O} 3$ reference strain (CDC 863-57) of Serratia marcescens. Carbohydr Res 187, 295-301.

Oxley, D. \& Wilkinson, S. G. (1989c). Structural studies of a neutral polymer (the putative O10 antigen) isolated from the lipopolysaccharide of Serratia marcescens strain CDC 1287-54 (O10, H8). Carbohydr Res 187, 303-311.

Oxley, D. \& Wilkinson, S. G. (1989d). Structures of neutral glycans isolated from the lipopolysaccharides of reference strains for Serratia marcescens serogroups $\mathrm{O} 16$ and O20. Carbohydr Res 193, 241-248.

Oxley, D. \& Wilkinson, S. G. (1989e). Structure of a neutral polymer isolated from the lipopolysaccharide of the reference strain for Serratia marcescens serogroup O18. Carbohydr Res 195, 111-115.

Oxley, D. \& Wilkinson, S. G. (1989f). Structure of the O-specific galactan from the lipopolysaccharide of the reference strain for Serratia marcescens serogroup O24. Carbohydr Res 195, 117-122.

Oxley, D. \& Wilkinson, S. G. (1990a). Structure of the putative O23 antigen of Serratia marcescens. Carbohydr Res 196, 127-131.

Oxley, D. \& Wilkinson, S. G. (1990b). A common structure for neutral polymers isolated from the lipopolysaccharides of reference strains for Serratia marcescens serogroups O17 and O19. Carbohydr Res 198, 168-172.

Oxley, D. \& Wilkinson, S. G. (1990c). Structure of a neutral glycan isolated from the lipopolysaccharide of the reference strain for Serratia marcescens serogroup O22. Carbohydr Res 203, 247-251.
Oxley, D. \& Wilkinson, S. G. (1990d). Structural studies of acidic polymers produced by the O23 reference strain of Serratia marcescens, presence of amide-linked glutamic acid. Carbohydr Res 204, 85-91.

Oxley, D. \& Wilkinson, S. G. (1991a). Structure of a glucorhamnan from the lipopolysaccharide of Serratia marcescens strain S1254. Carbobydr Res 209, 319-322.

Oxley, D. \& Wilkinson, S. G. (1991b). Structure of the O21 antigen from Serratia marcescens. Carbobydr Res 212, 187-192.

Oxley, D. \& Wilkinson, S. G. (1991c). Structure of a mannan isolated from the lipopolysaccharide of the reference strain (S3255) for a new serogroup of Serratia marcescens. Carbobydr Res 212, 213-217.

Oxley, D. \& Wilkinson, S. G. (1991d). Structure of an acidic glycan present in the lipopolysaccharide extract from the reference strain for Serratia marcescens serogroup O18. Carbohydr Res 215, 293-301.

Oxley, D. \& Wilkinson, S. G. (1992a). Structure of an acidic glycan from the reference strain for Serratia marcescens serogroup O22. Carbohydr Res 231, 237-248.

Oxley, D. \& Wilkinson, S. G. (1992b). Structure of a neutral glycan from the lipopolysaccharides of reference strains for Serratia marcescens serogroups O2 and O3. FEMS Microbiol Lett 99, 209-212.

Pitt, T. L., Erdman, Y. J. \& Bucher, C. (1980). The epidemiological type identification of Serratia marcescens from outbreaks of infection in hospitals. $J$ Hyg 84, 269-283.

Rubin, S. J., Brock, S., Chamberland, M. \& Lyons, R. W. (1976). Combined serotyping and biotyping of Serratia marcescens. $J$ Clin Microbiol 3, 582-585.

Sedlăk, J., Dlabac, V. \& Motlikovã, M. (1965). The taxonomy of the Serratia genus. J Hyg Epidemiol Microbiol Immunol 9, 45-53.

Traub, W. H. (1981). Serotyping of Serratia marcescens, confirmation of five recently described new $\mathrm{O}$-antigens and characterisation of an additional O-antigen. Zentralbl Bakteriol 250, 307-311.

Traub, W. H. (1985). Serotyping of Serratia marcescens, identification of a new O-antigen (O24). Zentralbl Bakteriol 259, 485-488.

Traub, W. H. (1991). Serotyping of Serratia marcescens, detection of two new O-antigens (O25 and O26). Zentralbl Bakteriol 275, 495-499.

Westphal, O. \& Jann, K. (1965). Bacterial lipopolysaccharides, extraction with phenol-water and further applications of the procedure. Methods Carbohydr Chem 5, 83-91.

Wilkinson, S. G. (1990). Surface polysaccharides of Gram-negative bacteria, heterogeneity, multiplicity and degeneracy. In Cellular and Molecular Aspects of Endotoxin Reactions, pp. 95-102. Edited by A. Nowotny, J. J. Spizer \& E. J. Ziegler. Amsterdam: Elsevier Science Publishers.

Received 31 July 1997; revised 3 November 1997; accepted 10 November 1997. 